\title{
Exercise Testing in Chronic Respiratory Diseases: Basics and Clinical Implications
}

Denis E. O'Donnell, MD, Nicolle J. Domnik, PhD and J. Alberto Neder, MD, PhD

Division of Respiratory Medicine, Department of Medicine, Queen's University, Kingston, Ontario, Canada

\section{ABSTRACT}

Dyspnoea and exercise intolerance are common symptoms experienced by patients with various chronic lung diseases. Cardiopulmonary exercise testing provides a unique opportunity to objectively evaluate the respiratory system's ability to respond to the metabolic stress of exercise. Although widely underutilized, cardiopulmonary exercise testing can help to unravel the underlying mechanisms of exercise intolerance in a given individual. We propose a simple, ordered approach that measures symptom intensity, metabolic and ventilatory control parameters, and dynamic respiratory mechanics during a standardized incremental test to tolerance.

The aim of this concise review is to examine exercise pathophysiology in chronic obstructive pulmonary disease and interstitial lung disease. We demonstrate striking similarities in the physiological responses to exercise across these pathologically distinct conditions and provide evidence to support common underlying mechanisms of exertional dyspnoea and reduced exercise capacity. Finally, we discuss the clinical implications of these new advances in exercise pathophysiology in the context of targeted therapeutic manipulation. (BRN Rev. 2016;2:274-91)

Corresponding author: Denis E. O’Donnell, odonnell@queensu.ca

Key words: Chronic obstructive pulmonary disease. Dyspnoea. Exercise. Interstitial lung disease. Pulmonary mechanics. Pulmonary vascular disease. 


\section{INTRODUCTION}

Persistent exertional dyspnoea and the associated avoidance of physical activity are frequently the presenting symptoms of patients with chronic respiratory disease and ultimately lead to skeletal muscle deconditioning and perceived poor quality of life. Moreover, dyspnoea, physical inactivity, and reduced peak oxygen consumption $\left(\mathrm{V}_{2}\right)$ are inextricably linked and have been shown to predict earlier mortality in various pulmonary diseas$\mathrm{es}^{1-4}$. Exercise capacity in individuals cannot reliably be predicted by clinical assessment, and resting pulmonary function tests (PFTs) only weakly correlate with peak $\mathrm{VO}_{2}{ }^{5,6}$. Only laboratory cardiopulmonary exercise testing (CPET) provides an accurate assessment of the integrated responses of the metabolic, respiratory, cardiovascular, peripheral muscular, and perceptual (neurosensory) systems to graded increases in work rate. Thus, CPET uniquely permits a rigorous evaluation of the interface between the respiratory impairment caused by disease and the resulting exercise intolerance under measured physiological stress.

The proximate limitation of exercise performance in lung disease populations is routinely intolerable dyspnoea and leg discomfort, or their combination, and severe perceived respiratory discomfort usually occurs well before respiratory and cardiovascular physiological limitation ${ }^{7-9}$. Thus, understanding the underlying mechanisms of limiting exertional symptoms in individual patients is centrally important. The measurement of exertional symptoms using validated scales is an integral component of CPET and is required for comprehensive clinical interpretation ${ }^{10,11}$.
This review provides an ordered presentation of perceptual and physiological responses to incremental exercise in health and selected disease states: (i) perceptual responses: dyspnoea (Borg) ratings as a function of work rate (and/ or minute ventilation, $\dot{\mathrm{V}}_{\mathrm{E}}$ ); (ii) ventilatory control: $\dot{\mathrm{V}}_{\mathrm{E}}$ /work rate, $\dot{\mathrm{VO}}_{2} /$ work rate, $\dot{\mathrm{V}}_{\mathrm{E}} / \dot{\mathrm{VCO}}_{2} /$ work rate (where $\mathrm{VCO}_{2}$ represents physiological $\mathrm{CO}_{2}$ production, primarily from cellular metabolism, but also from production of $\mathrm{CO}_{2}$ from acid [e.g. lactic acid] after buffering by bicarbonate, $\left.\mathrm{HCO}_{3}^{+}\right), \mathrm{O}_{2}$ saturation/work rate, end-tidal $\mathrm{CO}_{2} /$ work rate, and ventilatory thresholds (e.g. $\dot{\mathrm{V} C \mathrm{CO}_{2}} / \mathrm{VO}_{2}$ inflection method, a measure of acid-base disturbance); (iii) dynamic respiratory mechanics: change in IC, IRV, $\mathrm{V}_{\mathrm{T}}$ and breathing frequency, all as a function of increasing work rate (or $\left.\dot{\mathrm{V}}_{\mathrm{E}}\right)^{6,12-17}$. Quantitative flow-volume loop analysis and cardio-circulatory responses are not discussed because of space constraints.

We compare the integrated responses to incremental cycle-exercise testing in patients with obstructive and restrictive lung disorders. This approach exposes similarities and differences in physiological responses to exercise across these diverse diseases, uncovering common mechanisms of dyspnoea and exercise intolerance. Finally, we consider the clinical implications of these physiological derangements in chronic respiratory diseases.

\section{CHRONIC OBSTRUCTIVE PULMONARY DISEASE}

\section{Physiological responses to exercise in mild COPD}

Epidemiological studies confirm that activity-related dyspnoea, physical inactivity, poor 
quality of life, and increased risk of mortality are present even in symptomatic smokers with only minor spirometric abnormalities ${ }^{18-20}$. The heterogeneous nature of the physiological impairment in such individuals can be uncovered by tests such as oscillometry and nitrogen washout and by more traditional tests of lung-diffusing capacity and volume measurement ${ }^{12,14-17,21}$. Established abnormalities in mild COPD include: increased alveolar-to-arterial $\mathrm{O}_{2}$ tension gradient $\left(\mathrm{P}(\mathrm{A}-\mathrm{a}) \mathrm{O}_{2}\right)$ during resting breathing ${ }^{14,22,23}$; reduced diffusing capacity for carbon monoxide $\left(\mathrm{D}_{\mathrm{L}} \mathrm{CO}\right)^{24}$; increased peripheral airways resistance ${ }^{25}$; maldistribution of alveolar ventilation ${ }^{26}$; expiratory flow limitation (EFL) and pulmonary gas trapping (increased RV/TLC); and reduced $\mathrm{IC}^{12,14-17}$.

During incremental exercise, dominant abnormalities include: (i) increased chemo-stimulation of bulbopontine respiratory centres secondary to the effects of high physiological dead space, indirectly reflected by higher $\dot{\mathrm{V}}_{\mathrm{E}}$ / $\dot{\mathrm{VCO}} 2$ nadir and steeper $\dot{\mathrm{V}}_{\mathrm{E}}-\dot{\mathrm{V} C O}$ slope and; (ii) increased airways resistance and dynamic lung hyperinflation (DH), an acute, variable increase in end-expiratory lung volume [EELV] above its resting value) due to the combined effects of peripheral airway disease, EFL, and increased ventilatory demand (i.e. increased central inspiratory neural drive) $)^{14-16}$ (Fig. 1). Increased mechanical loading of the muscles and dynamic functional muscle weakness (muscle fibre shortening and increased velocity of shortening) means that efferent cortical motor output to the respiratory muscles must increase to maintain adequate force generation $^{27}$. Combined reductions in IC during exercise (due to increased EELV) and higher inspiratory neural drive (due to pulmonary gas exchange disruption and increased mechanical loading) in COPD force critical mechanical constraints and higher exertional dyspnoea ratings earlier in exercise than in healthy controls $^{12,14-17}$ (Fig. 1). This is more easily appreciated by examining the behaviour of dynamic IRV than by traditional assessments of breathing reserve $\left(\dot{\mathrm{V}}_{\mathrm{E}}\right.$ as a fraction of maximal ventilatory capacity, MVC), which can be misleading in mild $\mathrm{COPD}^{12,28}$.

\section{Physiological responses to exercise with more advanced COPD}

Similar derangements of pulmonary gas exchange, dynamic respiratory mechanics, and muscle function are present in more advanced COPD; however, they are more pronounced at significantly lower $\dot{\mathrm{V}}_{\mathrm{E}}$ and work rate (Fig. 2 and 3$)^{6,29}$.

\section{INCREASED INSPIRATORY NEURAL DRIVE}

During exercise, feed-forward efferent activation from respiratory control centres to the respiratory muscles rises in parallel with increased motor command output to the locomotor muscles ${ }^{30}$. In moderate-to-severe COPD (Fig. 2), the progressively increasing intrinsic mechanical loading of the functionally weakened respiratory muscles requires increases in efferent motor drive (from the motor cortex) to achieve a given force generation ${ }^{31,32}$. Additionally, reflex stimulation of central and peripheral chemoreceptors occurs as a result of: (i) $\dot{V}_{\mathrm{A}} / \mathrm{Q}$ abnormalities (decreased ventilatory efficiency, high ventilation-perfusion $\left(\dot{\mathrm{V}}_{\mathrm{A}} / \mathrm{Q}\right)$ lung units, and increased physiological 
A

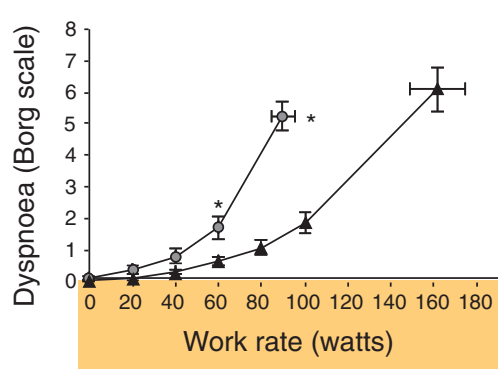

D
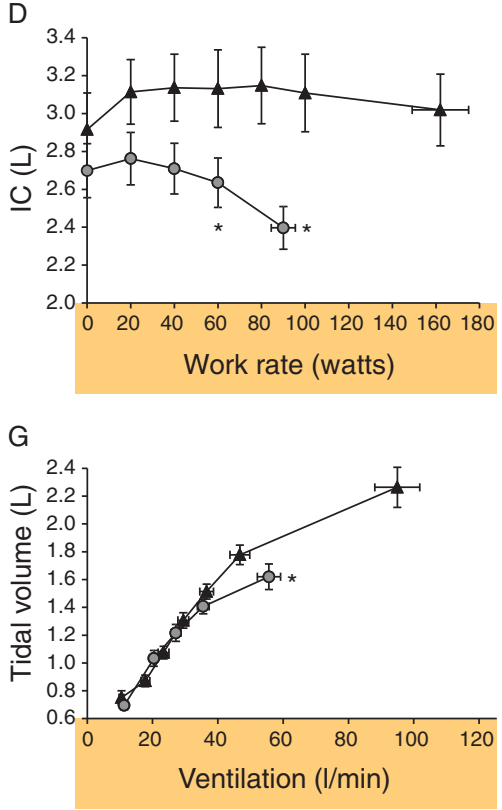

B

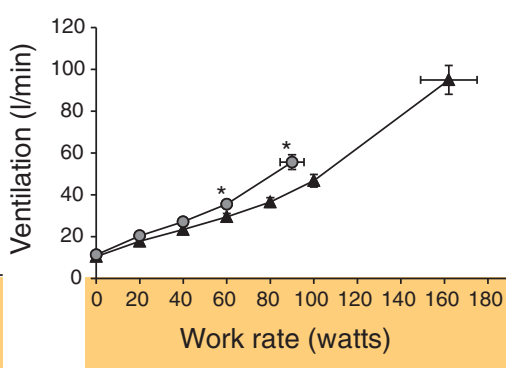

E
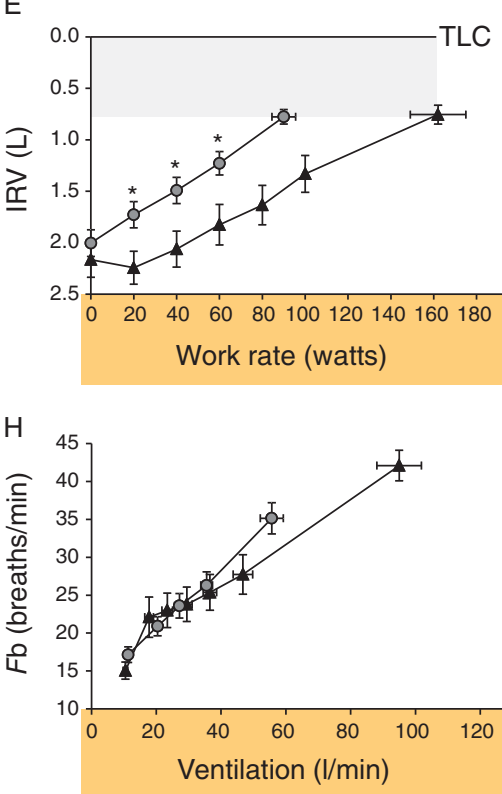

Healthy
C
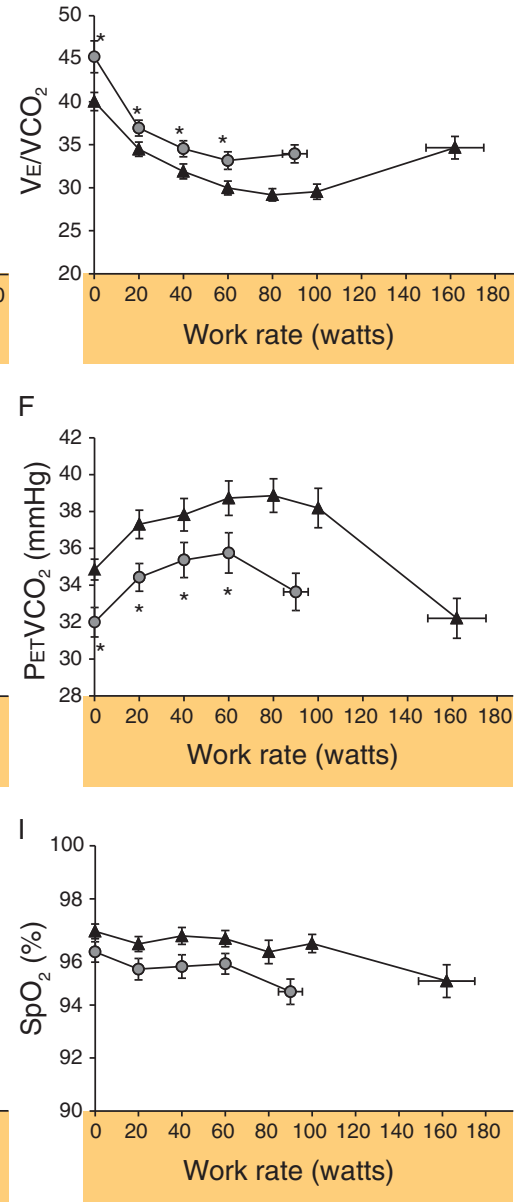

Figure 1. Proposed panel displays during interpretation of an incremental exercise test. Data showing selected perceptual, ventilatory control, and dynamic respiratory mechanics to incremental cycle exercise in patients with mild COPD and age-matched healthy controls. Values are mean \pm standard error of mean. ${ }^{*} p<0.05$ mild COPD versus healthy controls at rest, at standardized work rates, or at peak exercise (reproduced with permission from Chin et al. ${ }^{12}$ ).

$\mathrm{Fb}$ : breathing frequency; IC: inspiratory capacity; IRV: inspiratory reserve volume; $\mathrm{P}_{\mathrm{ET}} \mathrm{CO}_{2}$ : partial pressure of end-tidal carbon dioxide; $\mathrm{SpO}_{2}$ : oxygen saturation by pulse oximetry; $\dot{\mathrm{V}}_{\mathrm{E}} / \dot{\mathrm{V}}_{\mathrm{E}} \mathrm{CO}_{2}$ : ventilatory equivalent for carbon dioxide.

dead space) $)^{14,29,33}$; (ii) critical arterial oxygen $\left(\mathrm{O}_{2}\right)$ desaturation (low $\dot{\mathrm{V}}_{\mathrm{A}} / \mathrm{Q}$ lung units and reduced systemic mixed venous $\mathrm{O}_{2}$ in the blood) ${ }^{34,35}$; and (iii) increased acid-base disturbances (e.g. early metabolic acidosis) due to deconditioning or impaired cardiac function ${ }^{36,37}$. In advanced COPD, alveolar hypoventilation with $\mathrm{CO}_{2}$ retention can occur, reflecting critical mechanical limitation and respiratory muscle dysfunction, particularly in the setting of high physiological dead space and restricted $V_{\mathrm{T}}$ expansion ${ }^{38,39}$. Finally, the negative hemodynamic consequences of resting and dynamic hyperinflation may reduce cardiac 

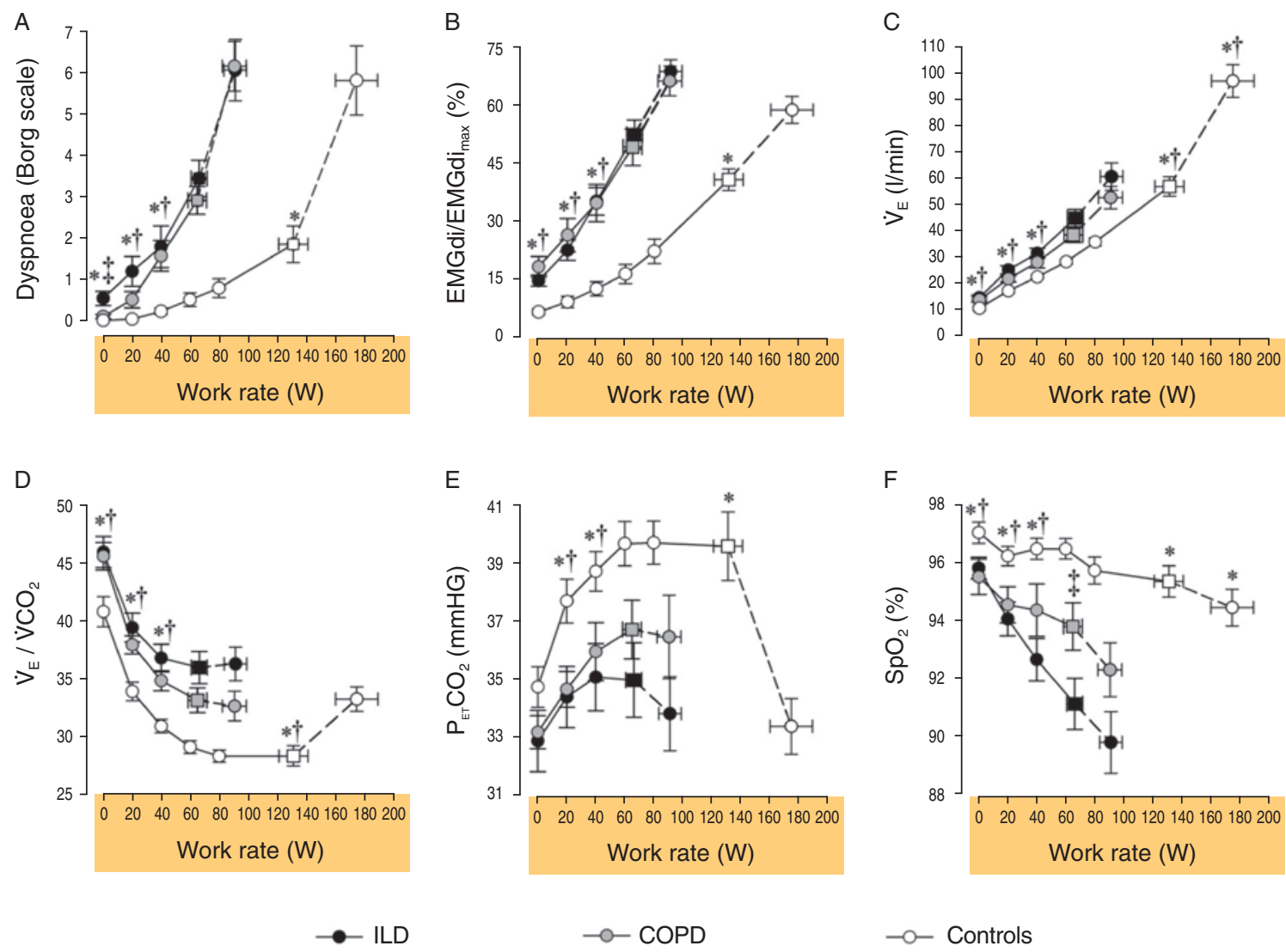

$\rightarrow-$ COPD

$\multimap-$ Controls

Figure 2. Dyspnoea intensity (Borg units), diaphragm electromyography and selected ventilatory and indirect gas exchange responses to incremental cycle exercise test in patients with moderate COPD, interstitial lung disease, and age-matched healthy controls. Values are mean \pm standard error of mean. Square symbols represent tidal volume-ventilation inflection points. ${ }^{*} \mathrm{p}<0.05$ COPD versus interstitial lung disease versus healthy controls at rest, at standardized work rates or at peak exercise (reproduced with permission from Faisal et al. ${ }^{13}$ ). EMGdi/EMGdi ${ }_{\text {max }}$ : index of inspiratory neural drive to the crural diaphragm; ILD: interstitial lung disease; $\mathrm{P}_{\mathrm{ET}} \mathrm{CO}_{2}$ : partial pressure of end-tidal carbon dioxide; $\mathrm{SpO}_{2}$ : oxygen saturation by pulse oximetry; $\dot{\mathrm{V}}_{\mathrm{E}}$ : minute ventilation; $\dot{\mathrm{V}}_{\mathrm{E}} / \dot{\mathrm{V}}_{\mathrm{E}} \mathrm{CO}_{2}$ : ventilatory equivalent for carbon dioxide.

output and $\mathrm{O}_{2}$ delivery to the contracting peripheral muscles, amplifying metabolic acidosis and ventilatory stimulation ${ }^{40-43}$.

\section{ABNORMAL DYNAMIC RESPIRATORY MECHANICS}

Increased respiratory motor drive and respiratory muscle effort occur due to increased elastic loading (including increased inspiratory threshold loading due to the effect of intrinsic positive end-expiratory pressure), decreased dynamic lung compliance and increased resistive loading of the respiratory muscles ${ }^{13,44}$. Inspiratory capacity is a useful noninvasive marker of dynamic respiratory mechanics in pulmonary diseases as it indicates how close the patient is breathing to TLC. In COPD, critical dynamic mechanical constraints are indicated by $\mathrm{DH}$ and by premature encroachment of end-inspiratory lung volume (EILV) 

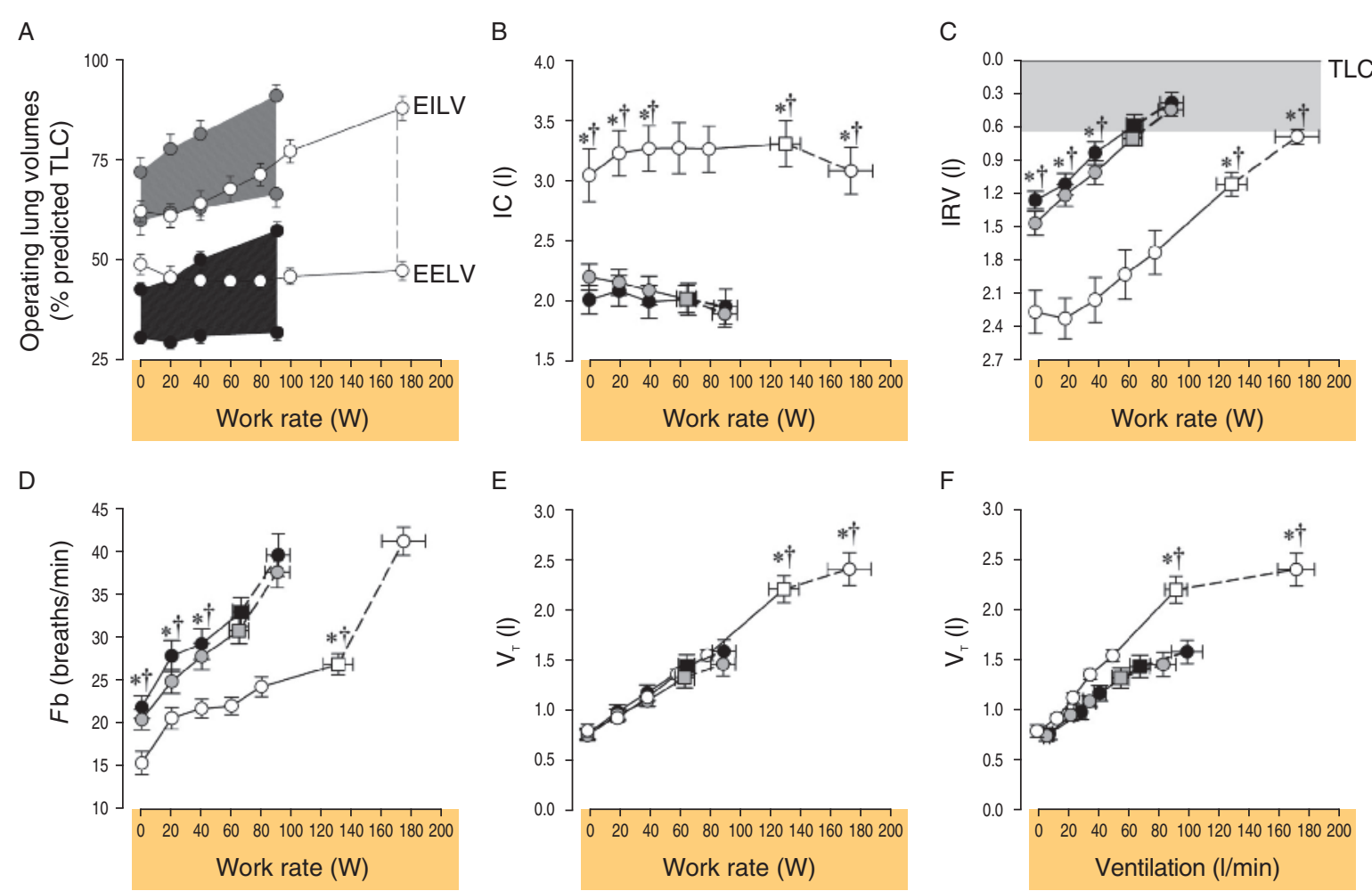

$\mathrm{F}$

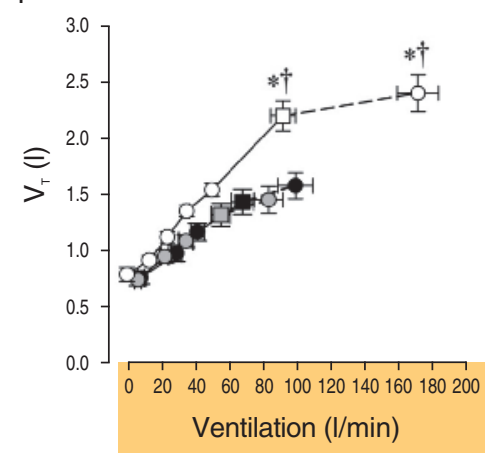

ILD

$\multimap-$ COPD

$-\infty-$ Controls

FIgURE 3. Operating lung volumes and breathing frequency during incremental cycle exercise in patients with moderate COPD, interstitial lung disease and age-matched healthy controls. Values are mean \pm standard error of mean. Square symbols represent tidal volumeventilation inflection points. ${ }^{*} \mathrm{p}<0.05$ chronic obstructive pulmonary disease (COPD) versus healthy controls at rest, at standardized work rates, or at peak exercise. The areas in panel $A$ that are shaded represent the tidal volume excursions in normal (white), COPD (grey), and ILD (black). The grey area on panel C, represents the critically reduced IRV (reproduced with permission from Faisal et al. ${ }^{13}$ ).

EELV: end-expiratory lung volume; EILV: end-inspiratory lung volume; Fb: breathing frequency; IC: inspiratory capacity; ILD: interstitial lung disease; IRV: inspiratory reserve volume; TLC: total lung capacity; $V_{\mathrm{T}}$ : tidal volume.

on TLC, i.e. the attainment of a critically reduced IRV (Fig. 3) ${ }^{6,45}$. Thus, $\mathrm{V}_{\mathrm{T}}$ becomes positioned close to TLC and the upper reaches of the S-shaped pressure-volume relation of the relaxed respiratory system, where compliance is decreased and the inspiratory muscles are functionally weakened. This explains the blunted $V_{T}$ response and relative tachypnoea of COPD. Increased breathing frequency and velocity of shortening of inspiratory muscles causes further functional weakness of the inspiratory muscles ${ }^{46}$. Expiratory muscle activity is relatively increased in COPD, but fails to prevent $\mathrm{DH}^{47,48}$. However, excessive expiratory muscle recruitment may have deleterious cardiac effects, which further compromise exercise performance ${ }^{49,50}$. Evidence that respiratory muscle fatigue is present at the limits of tolerance in advanced COPD is inconclusive, but some degree of dynamic functional weakness of the overloaded inspiratory muscles is measurable in 
such patients ${ }^{51}$. Overt "static" (resting) inspiratory muscle weakness is reported in a subset of patients and is multifactorial ${ }^{52,53}$. While not further discussed in the present work, inspiratory muscle adaptations to chronic hyperinflation (including, but not limited to, alterations in the relative amounts of type I versus II fibres, diaphragm shortening, and improved endurance characteristics) can help prevent, and sometimes overcome, static inspiratory muscle weakness ${ }^{54}$. For a detailed discussion of the impact of COPD on peripheral muscle function, please see a recent review by Maltais et al. ${ }^{55}$.

\section{WORSENING VENTILATORY EFFICIENCY WITH ADVANCING COPD}

The ventilatory response to exercise is coupled to metabolic demand, $\mathrm{VCO}_{2}$, throughout incremental exercise: $\dot{\mathrm{V}}_{\mathrm{E}} / \mathrm{VCCO}_{2}=1 /\left[\mathrm{PaCO}_{2} \times\right.$ $\left.\left(1-\mathrm{V}_{\mathrm{D}} / \mathrm{V}_{\mathrm{T}}\right)\right]$, where $\mathrm{V}_{\mathrm{D}}$ is the volume of dead space. In other words, $\dot{\mathrm{V}}_{\mathrm{E}} / \mathrm{V} \mathrm{CO}_{2}$ is higher (i.e. ventilation is less "efficient") the lower the level at which arterial partial pressure of $\mathrm{CO}_{2}$ $\left(\mathrm{PaCO}_{2}\right)$ is regulated (i.e. $\mathrm{CO}_{2}$ set-point) and the greater the fraction of the breath is wasted in $\mathrm{V}_{\mathrm{D}}$. Poor ventilatory efficiency is a key physiological abnormality in symptomatic patients with largely preserved $\mathrm{FEV}_{1}{ }_{1}^{12,14-17,29,56}$. The physiological basis for this seems to stem from an enlarged $\mathrm{V}_{\mathrm{D}}$ per se, rather than a small $\mathrm{V}_{\mathrm{T}}$ or a low $\mathrm{PaCO}_{2}{ }^{14}$. In fact, added external $\mathrm{V}_{\mathrm{D}}$ predictably increases $\dot{\mathrm{V}}_{\mathrm{E}} / \dot{\mathrm{VCO}}_{2}$ in these patients ${ }^{12}$. Regardless of the mechanism(s), the excessive ventilatory response erodes the mechanical reserves, thereby contributing to exertional dyspnoea and exercise intolerance ${ }^{12,14-17,56}$. Similar to heart failure $^{57}, \mathrm{~V}_{\mathrm{D}} / \mathrm{V}_{\mathrm{T}}$ worsens in tandem with COPD severity $^{39}$. Interestingly, while the most commonly used parameter of ventilatory efficiency $\left(\dot{\mathrm{V}}_{\mathrm{E}}-\dot{\mathrm{V} C O}_{2}\right.$ slope $)$ increases from mild to severe heart failure ${ }^{58}$, it decreases in severe to very severe versus milder COPD ${ }^{29}$. This seemingly paradoxical finding is explained by worsening mechanical constraints to $\dot{\mathrm{V}}_{\mathrm{E}}$ increase ${ }^{39}$ and, in end-stage disease, to hypercapnia ${ }^{38,59}$. Thus, $\dot{\mathrm{V}}_{\mathrm{E}}-\dot{\mathrm{V} C O}_{2}$ analysis cannot be used as a surrogate for measurement of physiological dead space in patients with limiting mechanical constraints.

\section{Exertional dyspnoea in COPD}

Exercise performance in COPD is primarily limited by ventilatory factors and accompanying intolerable respiratory discomfort. Progressive reduction of resting IC (as resting lung hyperinflation increases) with disease progression helps explain the diminishing operating limits for $\mathrm{V}_{\mathrm{T}}$ expansion and progressively earlier attainment of a minimal IRV during exercise (Fig. 4) ${ }^{6}$. The point at which $\mathrm{V}_{\mathrm{T}}$ reaches a critical minimal IRV is important during exercise. This is where the disparity between increasing inspiratory neural drive and the muscular response of the respiratory system abruptly widens, i.e. where neuromechanical dissociation (NMD) begins, and marks the threshold beyond which dyspnoea intensity rises sharply to intolerable levels $s^{6,60,61}$. The fact that increased inspiratory neural drive and NMD contribute to activity related dyspnoea and exercise intolerance in COPD is supported by studies showing that bronchodilator therapy, which improves dynamic mechanics (increases resting IC), delays mechanical limitation and partially restores neuromechanical coupling, thereby delaying the dyspnoea 

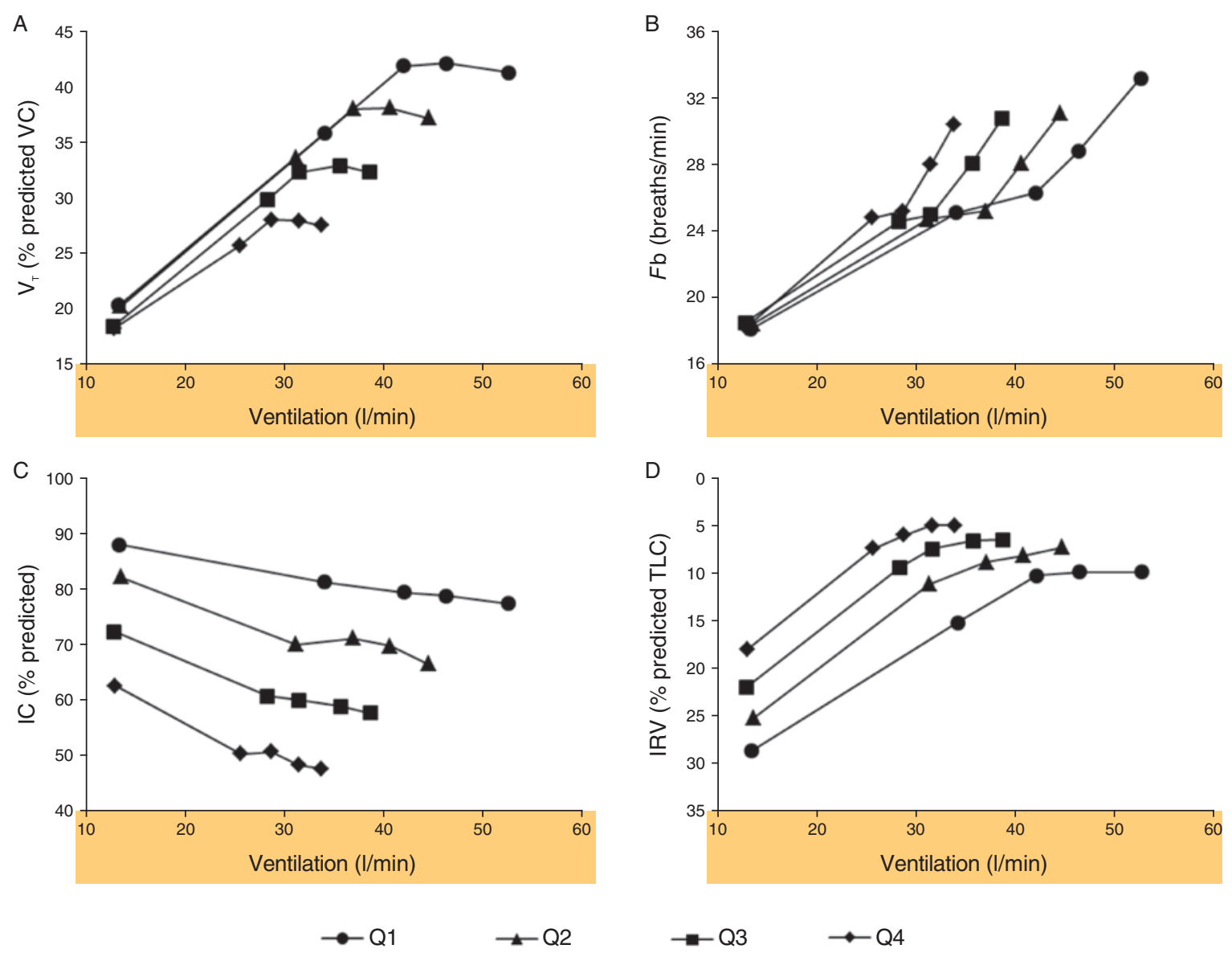

Figure 4. Tidal volume, breathing frequency, dynamic inspiratory capacity, and inspiratory reserve volume are shown plotted against minute ventilation in four disease severity quartiles based on forced expiratory volume in 1 second percentage predicted during constant work rate exercise in patients with chronic obstructive pulmonary disease (COPD). Note the clear inflection (plateau) in the tidal volume/ minute ventilation relationship, which coincides with a simultaneous inflection in the inspiratory reserve volume. After this point, further increases in minute ventilation are accomplished by accelerating the breathing frequency. Data plotted are mean values at steady-state rest, isotime (i.e. $2 \mathrm{~min}, 4 \mathrm{~min}$ ), the tidal volume/minute ventilation inflection point and peak exercise (reproduced with permission from O'Donnell et al. $\left.{ }^{6}\right)$.

Fb: breathing frequency; IC: inspiratory capacity; IRV: inspiratory reserve volume; TLC: total lung capacity; VC: vital capacity; $\mathrm{V}_{\mathrm{T}}$ : tidal volume.

threshold and prolonging exercise endurance time $^{60,61}$. Additionally, interventions that directly or indirectly reduce inspiratory neural drive and breathing frequency (e.g. supplemental oxygen, opiates, exercise training) can further improve dyspnoea and exercise tolerance $e^{5,62,63}$.

\section{RESTRICTIVE LUNG DISEASES}

Restrictive lung disorders (e.g. lung parenchymal diseases, neuromuscular disorders, chest wall restriction, and pulmonary resection) are characterized by an inability to expand $\mathrm{V}_{\mathrm{T}}$ appropriately during the increased 
metabolic demand of exercise. Here, we focus solely on the interstitial lung diseases (ILD). Exercise intolerance is multifactorial in ILD, but intolerable exertional symptoms and increased central inspiratory neural drive relative to maximum and abnormal cardiac function, in varying combinations, are important contributors ${ }^{64,65}$.

The pathophysiological hallmark of ILD is reduced static lung compliance (i.e. increased elastic lung recoil), which simultaneously restricts lung volume expansion and increases the driving pressure for expiratory airflow; thus, TLC, vital capacity (VC), and IC are reduced while the ratio of $\mathrm{FEV}_{1} / \mathrm{FVC}$ is usually increased. Disruption of the pulmonary microvasculature and the alveolar-capillary interface in ILD causes impaired gas exchange (i.e. decreased arterial oxygen saturation $\left(\mathrm{SaO}_{2}\right)$ and widened $\mathrm{P}(\mathrm{A}-\mathrm{a}) \mathrm{O}_{2}$ ), and a decreased diffusing capacity for carbon monoxide $\left(\mathrm{D}_{\mathrm{L}} \mathrm{CO}\right)^{64,66-68}$. At rest, arterial blood gases may appear normal or reveal mild hypoxemia and a compensated respiratory alkalosis ${ }^{69}$. The increased ventilatory demand secondary to increased $\dot{\mathrm{V}}_{\mathrm{A}} / \mathrm{Q}$ abnormalities and coupled with increased elastic loading of the inspiratory muscles results in increased work and oxygen cost of breathing at rest in ILD $^{13,69}$.

\section{Physiological responses to exercise in interstitial lung disease}

\section{INCREASED RESPIRATORY NEURAL DRIVE}

Similar to COPD, the central drive to breathe is increased when metabolic and ventilatory demands acutely increase during exercise in patients with ILD versus healthy individuals ${ }^{13}$
(Fig. 3). This reflects (in highly variable combinations) the increased chemostimulation of central respiratory control centres and increased efferent motor output as a result of increased elastic loading of the respiratory muscles $^{70}$.

\section{INCREASED REFLEX CHEMOSTIMULATION}

As for COPD, increased chemostimulation in ILD is similarly the result of the effects of wasted ventilation (high $\dot{\mathrm{V}}_{\mathrm{E}} / \dot{\mathrm{V} C O}_{2}$ ) (Fig. 2): reduced efficiency of $\mathrm{CO}_{2}$ elimination and/ or relative alveolar hyperventilation due to changes in the $\mathrm{CO}_{2}$ set-point ${ }^{71}$. Critical arterial hypoxemia with widened $\mathrm{P}(\mathrm{A}-\mathrm{a}) \mathrm{O}_{2}$ is common during exercise in more severe disease ${ }^{72-75}$ and can occur in early ILD, even before resting PFTs show overt impairment in $\mathrm{D}_{\mathrm{L}} \mathrm{CO}$ and lung mechanics ${ }^{76-78}$.

The mechanisms of arterial oxygen desaturation include: inter- and intra-regional $\dot{\mathrm{V}}_{\mathrm{A}} / \mathrm{Q}$ inequalities in the lungs, low mixed venous oxygen concentration in the setting of low $\dot{\mathrm{V}}_{\mathrm{A}} / \mathrm{Q}$, diffusion disequilibrium with decreased pulmonary capillary transit time and, in some individuals, increased intra-cardiac and intra-pulmonary right-to-left shunting ${ }^{72-75}$. Alveolar hypoventilation is not commonly reported during exercise, even in advanced ILD, but severe $V_{T}$ restriction in the setting of a fixed high $\mathrm{V}_{\mathrm{D}}$ can potentially cause $\mathrm{CO}_{2}$ retention. Correlations have been found between the low resting $\mathrm{D}_{\mathrm{L}} \mathrm{CO}$ and arterial hypoxemia during exercise ${ }^{72}$, but there is considerable overlap in this relationship, particularly in patients with mild-to-moderate disease. 
Additional sources of ventilatory stimulation in ILD may include: altered reflex afferent activation of vagal receptors in the lung parenchyma and airways ${ }^{79}$; early metabolic acidosis due to deconditioning, and increased peripheral muscle ergo-receptor activation. As in COPD, additional ventilatory stimulation may arise in some individuals due to comorbidities or complications such as obesity (i.e. increased metabolic loading), pulmonary arterial hypertension, emphysema, and cardio-circulatory disease ${ }^{13,64,69}$.

\section{DYNAMIC MECHANICAL CONSTRAINTS}

During exercise, patients with ILD experience dynamic restrictive mechanical constraints, which, as already seen in COPD, are reflected by high $\mathrm{V}_{\mathrm{T}} / \mathrm{IC}$ ratios and an early plateau of the $\mathrm{V}_{\mathrm{T}}$ response as it reaches the critical minimal IRV earlier in exercise compared with healthy individuals (Fig. 3). Accordingly, tachypnoea is the only available option to respond to the high inspiratory neural drive. This rapid and shallow pattern of breathing helps attenuate the effects of increased elastic work of breathing and attendant respiratory discomfort. However, this pattern of breathing itself has been linked to increased sensations of breathless in ILD ${ }^{80}$. As ventilation increases during exercise, the work of breathing increases dramatically in order to overcome the high elastic loads of the stiff lungs and chest wall while breathing close to the reduced $\mathrm{TLC}^{81}$. Moreover, increased velocity of shortening (which can be assessed via surrogate measurement of inspiratory flow, breathing frequency, and duty cycle) of the inspiratory muscles results in dynamic functional inspiratory muscle weakness ${ }^{82-85}$. Weakness, i.e. a "failure to generate the required or expected force on first testing" ${ }^{\prime \prime 6}$, can be impacted by changes in static or dynamic length or velocity elements ${ }^{87}$, and occurs independently of muscular fatigue, which is defined as a reversible "loss in capacity for developing force and/or velocity of a muscle, resulting from muscle activity under load and which is reversed by rest" ${ }^{\prime \prime 8}$. Consequently, in most instances, exercise intolerance in ILD is explained by true ventilatory limitation and associated severe dyspnoea.

In ILD, the pressure-volume relationship of the entire respiratory system is contracted along its volume axis, but retains its $\mathrm{S}$-shape. As illustrated in figure 5, the resting IC and IRV are usually diminished. With exercise, EILV encroaches further on the upper alignment extreme of the pressure-volume relationship "beyond the S-bend" where there is significant elastic loading. Tidal volume reaches a plateau at $50-60 \%$ of the reduced VC (or $\sim 70 \%$ of IC) early in exercise: minimal dynamic IRV and the $\mathrm{V}_{\mathrm{T}}$ plateau are reached together with a step increase in breathing frequency.

A few studies report that IC remains largely unaltered throughout exercise, reflecting a diminished expiratory reserve volume (ERV) and a reduced ability to decrease EELV ${ }^{89,90}$. However, EFL has been described in some patients with ILD and may reflect co-existent airway obstruction as a result of smoking or actual airway involvement as part of the interstitial disease process (e.g. hypersensitivity pneumonitis) $)^{89,91}$. Interestingly, the presence of EFL in ILD was associated with worsening dyspnoea compared with those with ILD with normal airway function ${ }^{89}$. 

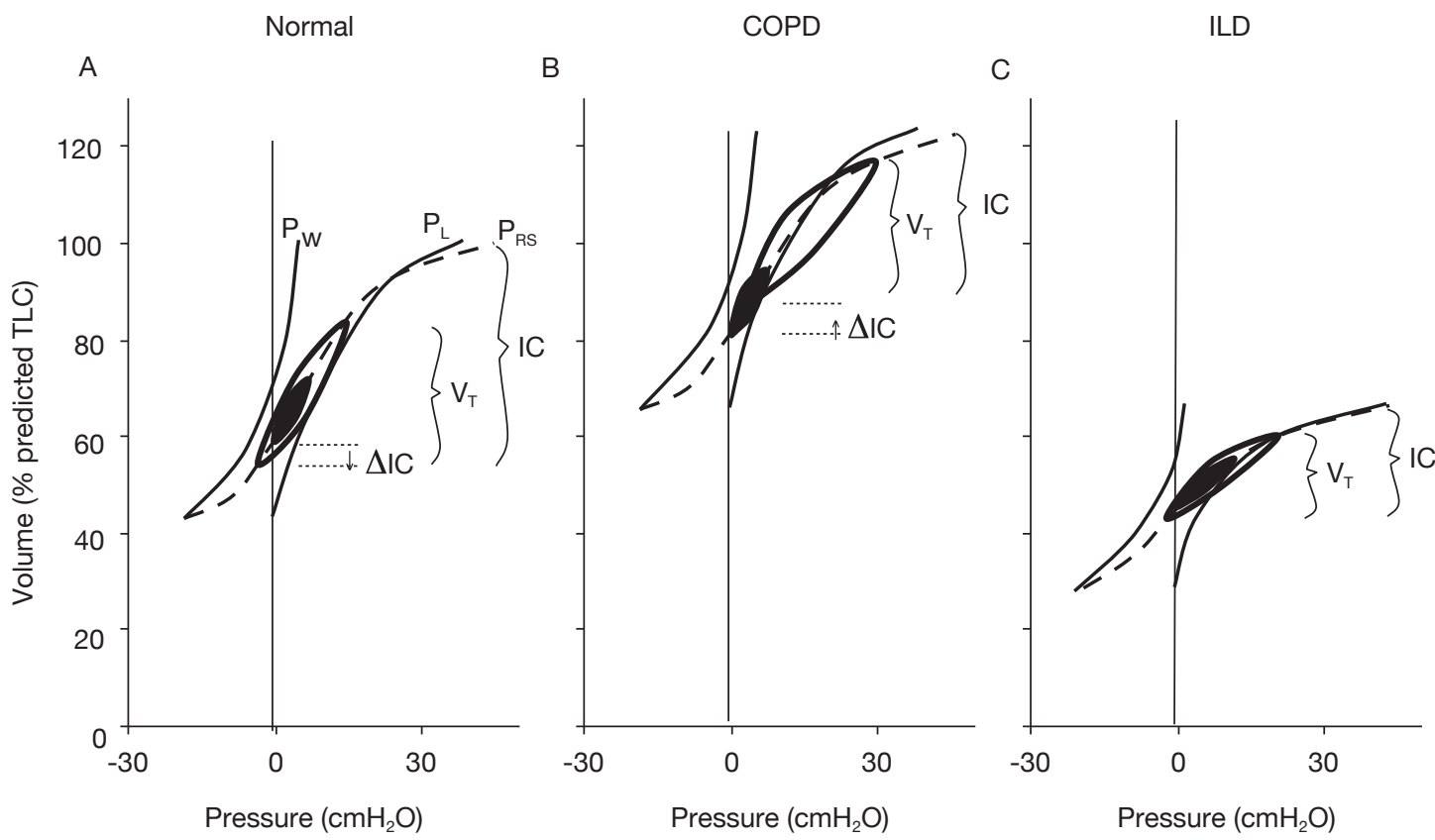

Figure 5. Pressure-volume curves (pressure: $\mathrm{cmH}_{2} \mathrm{O}$, volume: \% predicted of total lung capacity) are shown for healthy (“Normal”, left panel), COPD (middle panel), and interstitial lung disease (right panel). Resting tidal volume is indicated by black ellipses, while tidal volume during exercise is indicated by hollow loops. Inspiratory capacity and inspiratory reserve volume are diminished in interstitial lung disease as compared with healthy individuals. From resting tidal volume to exercise, end-inspiratory lung volume encroaches on the upper, aligned portion of the pressure-volume curve (near total lung capacity) in interstitial lung disease. This is akin to changes in COPD, where the upper limit of tidal volume during activity approaches total lung capacity; however, end-expiratory lung volume increases concomitantly with this increase in end-inspiratory lung volume in chronic obstructive pulmonary disease (COPD) versus interstitial lung disease.

IC: inspiratory capacity; ILD: interstitial lung disease; $\mathrm{P}_{\mathrm{L}}$ : transpulmonary pressure; $\mathrm{P}_{\mathrm{RS}}$ : trans-respiratory system pressure;

$\mathrm{P}_{\mathrm{W}}$ : transthoracic pressure; TLC: total lung capacity; $\mathrm{V}_{\mathrm{T}}$ : tidal volume.

Inspiratory muscle function is often relatively preserved in patients with ILD, reflecting the training effects of intrinsic mechanical loading and the mechanical advantage of the inspiratory muscles at the lower than normal operating lung volumes ${ }^{90,92}$. However, in some individuals, involvement of these muscles in the underlying systemic inflammatory disease process, the effects of cachexia, high-dose oral steroids, malnutrition, electrolytic disturbances, and global skeletal muscle deconditioning may have a deleterious impact on function ${ }^{93}$.

\section{Exertional dyspnoea in interstitial lung disease}

The increase in intensity of dyspnoea during CPET correlates well with the increasing amplitude of the neural inspiratory drive to the diaphragm, the increasing oesophageal pressure relative to maximum, and the increasing $\mathrm{V}_{\mathrm{T}} / \mathrm{IC}$ ratio - a measure of prevailing mechanical constraints ${ }^{13,90}$. Thus, as in COPD, dyspnoea rises as a function of the increasing neural drive to the inspiratory 
muscles, increased contractile respiratory muscle effort, and intrinsic restriction of appropriate $\mathrm{V}_{\mathrm{T}}$ expansion. Similarly, interventions that attenuate chemostimulation, delay the rise in metabolic $\dot{\mathrm{VCO}_{2}}$ (e.g. exercise training), or reduce efferent output from respiratory centres (e.g. oxygen supplementation, opiates) alleviate exertional dyspnoea in patients with ILD $67,94,95$.

\section{COMPARISON OF EXERCISE RESPONSES IN COPD AND INTERSTITIAL LUNG DISEASE}

At first glance, COPD and ILD are remarkably different in underlying pathology, static respiratory mechanics (i.e. absolute lung volumes), nature and extent of the mechanical loads, and respiratory muscle characteristics and recruitment patterns. The major differences in mechanical loading and activation patterns of the respiratory muscles have recently been highlighted ${ }^{13}$. Patients with ILD often have better preservation of inspiratory muscle force-generating capacity, reflecting the mechanical advantage of lower operating lung volumes. Furthermore, such patients, unlike those with COPD, do not usually have to contend with inspiratory threshold and resistive loading, and expiratory muscle activity is generally lower. However, clinically stable ILD patients generally have earlier onset of more severe gas exchange abnormalities during exercise than patients with COPD (Fig. 2). In COPD, $\mathrm{V}_{\mathrm{T}}$ is restricted from below by the effects of resting and dynamic lung hyperinflation, whereas in ILD, the restriction is from above, reflecting the reduced TLC and IRV. Remarkably, ventilation, breathing pattern, and the behaviour of dynamic IRV during conventional CPET are similar in obstructive and restrictive diseases (Fig. 3). It is clear that regardless of the precise mechanism of restriction, the inability to expand $\mathrm{V}_{\mathrm{T}}$ in response to the increasing inspiratory drive or effort during exercise contributes to low peak ventilatory capacity in both COPD and ILD.

\section{Common mechanisms of dyspnoea}

Dyspnoea during exercise in COPD and ILD fundamentally reflects an imbalance between the increased demand to breathe and the ability to meet that demand, and its intensity correlates closely with the following physiological ratios: $\dot{\mathrm{V}}_{\mathrm{E}}$ /MVC; oesophageal pressure (Pes/Pes $\left.{ }_{\max }\right), \mathrm{V}_{\mathrm{T}} / \mathrm{IC}$ or EILV/TLC, and inspiratory neural drive to the diaphragm relative to maximum diaphragmatic electromyogra-

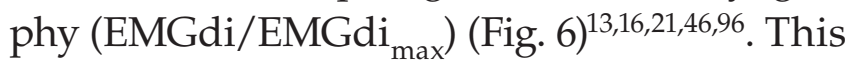
indicates that respiratory discomfort is provoked when there is critical encroachment on reserves of ventilatory output, muscle force generation, $\mathrm{V}_{\mathrm{T}}$ expansion, and inspiratory neural drive to the diaphragm ${ }^{13,16,21,46,96}$.

Current neurophysiological constructs propose that the intensity of dyspnoea rises with increasing tidal inspiratory efferent neural activity relative to the maximum possible neural activation (from bulbopontine and cortical motor centres in the brain) as indirectly represented by the above physiological ratios ${ }^{13,16,21}$. It is further postulated that concomitant increased central corollary discharge from control centres to the somatosensory cortex, where unpleasant respiratory sensations are consciously perceived, is a final common pathway $^{97,98}$ (Fig. 7). 

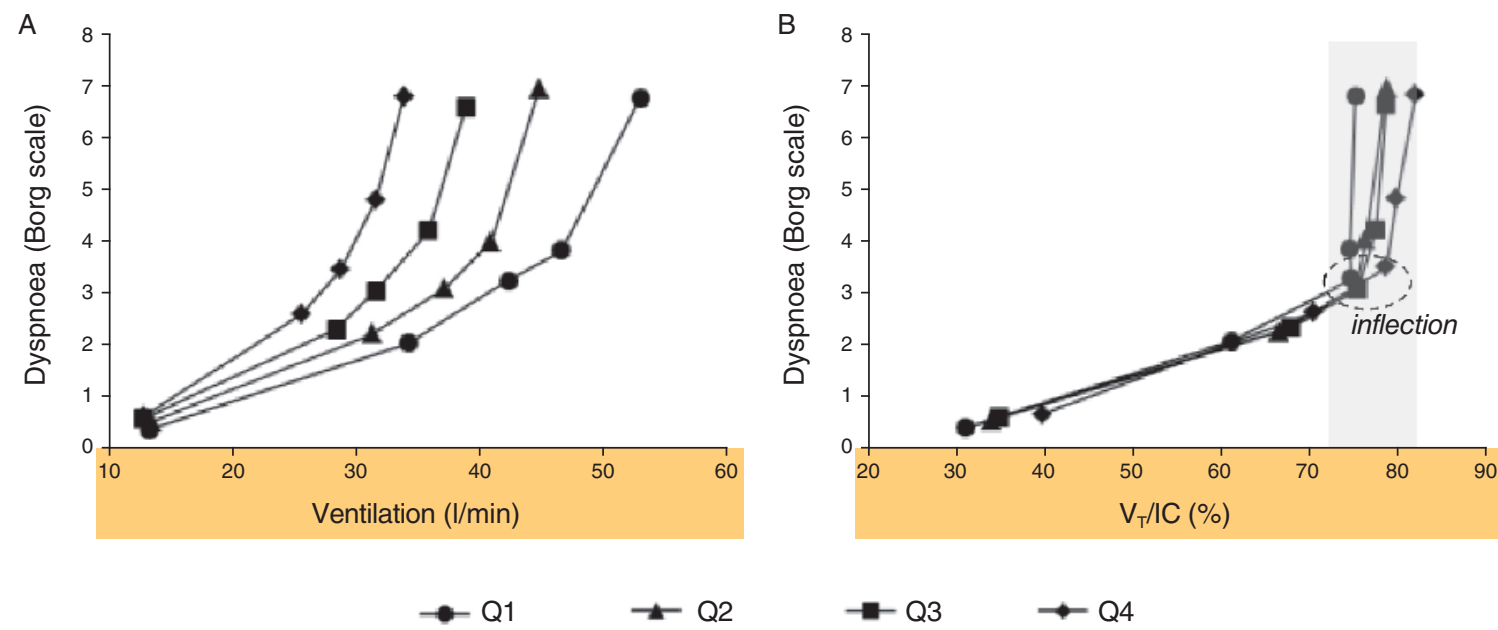

Figure 6. Inter-relationships are shown between exertional dyspnoea intensity, ventilation and the tidal volume/inspiratory capacity ratio in four disease severity quartiles based on forced expiratory volume in 1 second percentage predicted during constant work rate exercise in chronic obstructive pulmonary disease (COPD). After the tidal volume/inspiratory capacity ratio plateaus (i.e., the tidal volume inflection point), dyspnoea rises steeply to intolerable levels. There is a progressive separation of dyspnoea/minute ventilation plots with worsening quartile. Data plotted are mean values at steady-state rest, isotime (i.e. $2 \mathrm{~min}, 4 \mathrm{~min}$ ), the tidal volume/minute ventilation inflection point and peak exercise (reproduced with permission from O'Donnell et al. ${ }^{6}$ ).

IC: inspiratory capacity; $\mathrm{V}_{\mathrm{T}}$ : tidal volume.

Exertional dyspnoea at the limits of tolerance is qualitatively similar in COPD and ILD ${ }^{13,90,99}$ (Fig. 6). We postulate that the dominant qualitative respiratory sensations that allude to "unsatisfied inspiration" ("can't get enough air in") ultimately have their neurophysiological basis in the conscious awareness of a disparity between the increased drive to breathe and the restricted mechanical response of the respiratory system. At exercise termination in both COPD and ILD, central respiratory efferent drive reaches almost maximal values, but the respiratory muscle pump, which is overloaded and functionally weakened, responds inadequately to the increased electrical activation $^{13}$ (Fig. 6). Thus, despite near-maximal drive and effort, very little air enters the lungs with each breath $13,60,99,100$. This disparity is perceived as unpleasant and is the result of integration of efferent central outputs and multiple afferent peripheral inputs from the respiratory muscles chest wall and lungs (Fig. 7). In line with this theory, it has been repeatedly shown that external imposition of mechanical loads to impede respiration in healthy volunteers in the face of increasing chemostimulation reliably provokes respiratory sensations akin to "unsatisfied inspiration" $" 11,101,102$.

Although definitive experimental verification is lacking, it is believed that vagal afferent input from the lungs directly to the somatosensory cortex, or spinal input from mechanoreceptors in the respiratory muscle and chest wall, can directly induce unpleasant respiratory sensations that shape the clinical 
A

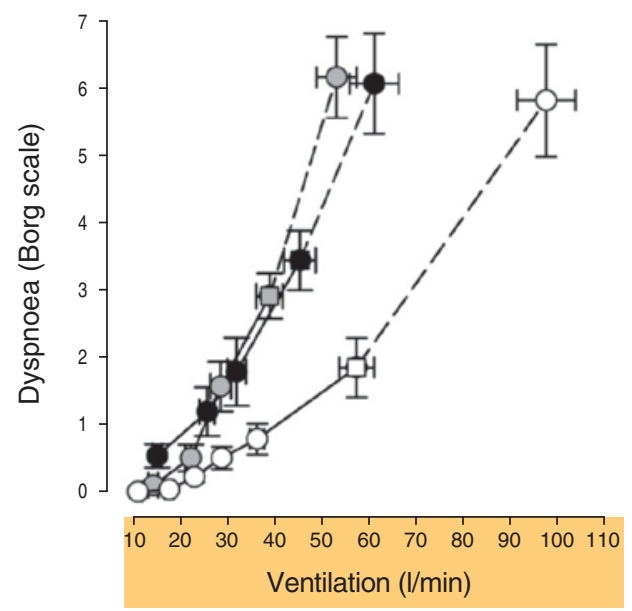

C

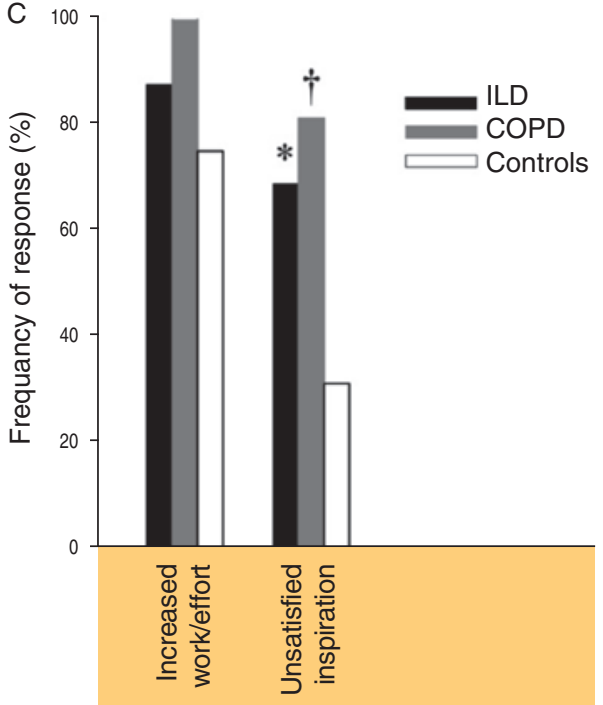

B

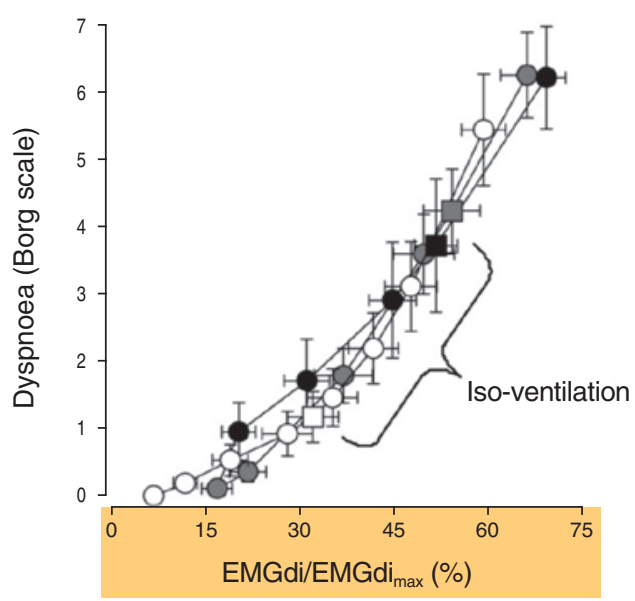

D

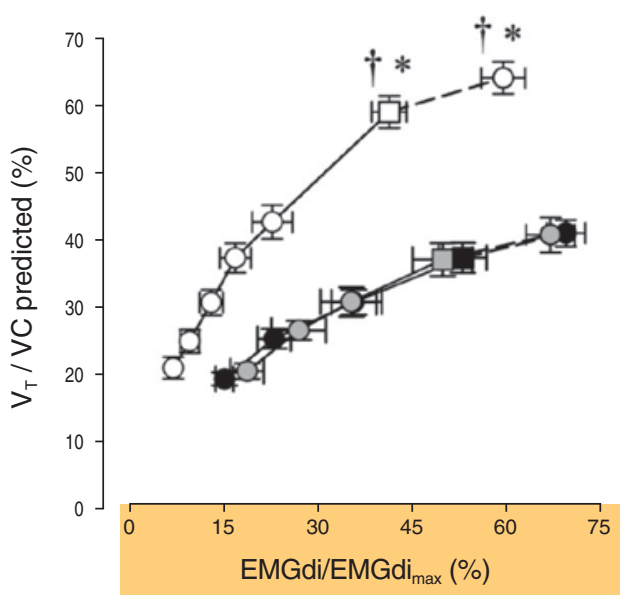

$-\mathrm{O}-$ Controls

Figure 7. Exertional dyspnoea intensity is shown relative to ventilation (a) and diaphragm electromyography relative to maximum (b) during incremental cycle exercise in patients with moderate chronic obstructive pulmonary disease (COPD), interstitial lung disease (ILD), and age-matched healthy controls. Panel (c) shows selected qualitative dyspnoea descriptors at the end of incremental cycle exercise in patients with moderate COPD, interstitial lung disease, and age-matched healthy controls. Panel (d) shows the relation between tidal volume as a fraction of predicted vital capacity and diaphragm electromyography relative to maximum. Square symbols represent the tidal volume-ventilation inflection points in panels $(a, c)$ and the point at the highest equivalent ventilation $(50 \mathrm{l} / \mathrm{min})$ in panel $(\mathrm{b})$. Values are mean \pm standard error of mean. ${ }^{*} p<0.05$ COPD versus interstitial lung disease versus healthy controls at rest, at standardized work rates or at peak exercise (reproduced with permission from Faisal et al. ${ }^{13}$ ).

EMGdi: diaphragmatic electromyography; EMGdi $_{\max }$ : diaphragmatic electromyography maximum; ILD: interstitial lung disease; VC: vital capacity; $\mathrm{V}_{\mathrm{T}}$ : tidal volume. 
expression of dyspnoea ${ }^{99}$. This notwithstanding, a recent study provides strong evidence that the relationship between increased dyspnoea intensity and increased inspiratory neural drive to the diaphragm during exercise is not affected by major disease-specific differences in afferent inputs from the airways, lung parenchyma, chest wall, and respiratory muscles.

Respiratory discomfort beyond a certain threshold evokes emotive responses, such as anxiety, fear, panic, or distress (Fig. 7). The threshold for affective distress likely varies between individuals and is thought to be linked to increased activation of limbic and paralimbic centres in the brain and associated over activation of sympathetic nervous system ${ }^{103-109}$.

\section{CONCLUSIONS AND CLINICAL IMPLICATIONS}

Traditional CPET focuses on measuring peak $\dot{\mathrm{V}} \mathrm{O}_{2}$ and incorporates a quantitative assessment of cardiac and ventilatory reserves as well as aerobic capacity ${ }^{110}$. The simple format proposed here extends this approach to include evaluation of perceived intensity of exertional dyspnoea and its origins. This assessment of ventilatory constraints based on breathing pattern and operating lung volumes is arguably more sensitive than crude assessments on breathing reserve $\left(\dot{\mathrm{V}}_{\mathrm{E}} / \mathrm{MVC}\right)$, at least in patients with milder COPD and ILD.

Cardiopulmonary exercise testing allows for a more comprehensive physiological characterization of pathophysiology in symptomatic patients in the early phases of COPD and ILD, whose pulmonary function tests are close to the normal range and whose dyspnoea seems disproportionate to resting PFT abnormalities. Using the approach outlined above, it is possible to uncover unanticipated abnormalities in $\dot{\mathrm{V}}_{\mathrm{E}} / \dot{\mathrm{VCO}}_{2}$, breathing pattern, and operating lung volumes, helping to explain the origin of dyspnoea in the individual. CPET can also expose hitherto unknown physiological abnormalities such as arterial oxygen desaturation, $\mathrm{DH}$ and impairment of cardio-circulatory function, which require further diagnostic evaluation and targeted treatment. For example, the finding of $\mathrm{DH}$ in a symptomatic patient with ILD might lead to a therapeutic trial of a bronchodilator. Other clinical scenarios in which CPET might influence disease management include: (i) demonstration of mechanical-ventilatory and/or gas exchange abnormalities limiting exercise tolerance in patients in whom deconditioning is a major confounder; (ii) pre-enrolment assessment in patients referred for exercise training in order to exclude cardiovascular/ischaemic abnormalities and guide the initial target training intensity; and (iii) risk prediction using submaximal, effort-independent measurements such as $\dot{\mathrm{V}}_{\mathrm{E}} / \dot{\mathrm{VCO}}_{2}$ nadir in patients with $\mathrm{COPD}^{29}$.

The finding that intolerable dyspnoea in COPD and ILD can be mostly explained by near-maximal inspiratory neural drive in the setting of a blunted respiratory system response underlines the formidable challenge faced by caregivers trying to alleviate their patients' dyspnoea and activity restriction. In both conditions $\dot{V}_{\mathrm{A}} / \mathrm{Q}$ abnormalities, which largely underpin the increased inspiratory neural drive, are often irreversible. It follows that in some COPD patients, bronchodilators, which improve mechanics but have little or 
no effect on the increased $\dot{\mathrm{V}}_{\mathrm{E}} / \mathrm{V} \mathrm{CO}_{2}$, may have only limited effects on dyspnoea alleviation.

Knowledge of the common mechanisms of
exertional dyspnoea in both COPD and ILD allows us to develop a cogent physiological rationale for personalized management, preferably in the context of pulmonary rehabilitation. Thus, interventions that reduce the heightened inspiratory neural drive (exercise training, supplemental $\mathrm{O}_{2}$ or opioid medication) can successfully ameliorate dyspnoea during physical activity in selected patients. Similarly, interventions that improve respiratory mechanics and dynamic respiratory muscle function (e.g. bronchodilators in COPD) can partially diminish NMD of the respiratory system and improve exercise intolerance.

\section{REFERENCES}

1. Oga T, Nishimura K, Tsukino M, Sato S, Hajiro T. Analysis of the factors related to mortality in chronic obstructive pulmonary disease: role of exercise capacity and health status. Am J Respir Crit Care Med. 2003;167:544-9.

2. Waschki B, Kirsten A, Holz O, et al. Physical activity is the strongest predictor of all-cause mortality in patients with COPD: a prospective cohort study. Chest. 2011;140:331-42.

3. Pinto-Plata VM, Cote C, Cabral H, Taylor J, Celli BR. The 6-min walk distance: change over time and value as a predictor of survival in severe COPD. Eur Respir J. 2004;23:28-33.

4. Ley B, Bradford WZ, Vittinghoff E, Weycker D, du Bois RM, Collard HR. Predictors of mortality poorly predict common measures of disease progression in idiopathic pulmonary fibrosis. Am J Respir Crit Care Med. 2016. [Epub ahead of print].

5. O'Donnell DE, Revill SM, Webb KA. Dynamic hyperinflation and exercise intolerance in chronic obstructive pulmonary disease. Am J Respir Crit Care Med. 2001;164:770-7.

6. O'Donnell DE, Guenette JA, Maltais F, Webb KA. Decline of resting inspiratory capacity in COPD: the impact on breathing pattern, dyspnea, and ventilatory capacity during exercise. Chest. 2012;141:753-62.

7. Killian KJ, Leblanc P, Martin DH, Summers E, Jones NL, Campbell EJ. Exercise capacity and ventilatory, circulatory, and symptom limitation in patients with chronic airflow limitation. Am Rev Respir Dis. 1992;146:935-40.

8. Hamilton AL, Killian KJ, Summers E, Jones NL. Symptom intensity and subjective limitation to exercise in patients with cardiorespiratory disorders. Chest. 1996;110:1255-63.

9. O'Donnell DE, Webb KA. Exertional breathlessness in patients with chronic airflow limitation. The role of lung hyperinflation. Am Rev Respir Dis. 1993;148:1351-7.

10. Borg GA. Psychophysical bases of perceived exertion. Med Sci Sports Exerc. 1982;14:377-81.
11. Gift AG. Validation of a vertical visual analogue scale as a measure of clinical dyspnea. Rehabil Nurs. 1989;14:323-5.

12. Chin RC, Guenette JA, Cheng S, et al. Does the respiratory system limit exercise in mild chronic obstructive pulmonary disease? Am J Respir Crit Care Med. 2013;187:1315-23.

13. Faisal A, Alghamdi BJ, Ciavaglia CE, et al. Common mechanisms of dyspnea in chronic interstitial and obstructive lung disorders. Am J Respir Crit Care Med. 2016;193:299-309.

14. Elbehairy AF, Ciavaglia CE, Webb KA, et al. Pulmonary gas exchange abnormalities in mild chronic obstructive pulmonary disease. Implications for dyspnea and exercise intolerance. Am J Respir Crit Care Med. 2015;191: 1384-94.

15. Elbehairy AF, Raghavan N, Cheng S, et al. Physiologic characterization of the chronic bronchitis phenotype in GOLD grade IB COPD. Chest. 2015; 147:1235-45.

16. Guenette JA, Chin RC, Cheng S, et al. Mechanisms of exercise intolerance in global initiative for chronic obstructive lung disease grade 1 COPD. Eur Respir J. 2014;44:1177-87.

17. Ofir D, Laveneziana P, Webb KA, Lam YM, O'Donnell DE. Mechanisms of dyspnea during cycle exercise in symptomatic patients with GOLD stage I chronic obstructive pulmonary disease. Am J Respir Crit Care Med. 2008, 177:622-9.

18. Furlanetto KC, Mantoani LC, Bisca G, et al. Reduction of physical activity in daily life and its determinants in smokers without airflow obstruction Respirology. 2014;19:369-75.

19. Woodruff PG, Barr RG, Bleecker E, et al. Clinical significance of symptoms in smokers with preserved pulmonary function. N Engl J Med. 2016;374: 1811-21.

20. Regan EA, Lynch DA, Curran-Everett D, et al. Clinical and radiologic disease in smokers with normal spirometry. JAMA Intern Med. 2015;175: 1539-49.

21. Elbehairy AF, Guenette JA, Faisal A, et al. On behalf of the Canadian Respiratory Research Network. Mechanisms of exertional dyspnea in symptomatic smokers without COPD. Eur Respir J. 2016;48:694-705.

22. Barbera JA, Ramirez J, Roca J, Wagner PD, Sanchez-Lloret J, Rodriguez-Roisin R. Lung structure and gas exchange in mild chronic obstructive pulmonary disease. Am Rev Respir Dis. 1990;141:895-901.

23. Rodriguez-Roisin R, Drakulovic M, Rodriguez DA, Roca J, Barbera JA, Wagner PD. Ventilation-perfusion imbalance and chronic obstructive pulmonary disease staging severity. J Appl Physiol (1985 ) 2009 Jun;106(6):1902-8.

24. Kirby M, Owrangi A, Svenningsen S, et al. On the role of abnormal DL(CO) in ex-smokers without airflow limitation: symptoms, exercise capacity and hyperpolarised helium-3 MRI. Thorax. 2013;68:752-9.

25. McDonough JE, Yuan R, Suzuki M, et al. Small-airway obstruction and emphysema in chronic obstructive pulmonary disease. N Engl J Med. 2011; 365:1567-75.

26. Buist AS. Early detection of airways obstruction by the closing volume technique. Chest. 1973;64:495-9.

27. Pride NB, Macklem PT. Lung Mechanics in Disease. In: Fishman AP, editor Handbook of Physiology. Bethesda, MD: American Physiological Society; 1986. p. 659-92.

28. Dempsey JA. Limits to ventilation (for sure!) and exercise (maybe?) in mild chronic obstructive pulmonary disease. Am J Respir Crit Care Med. 2013; 187:1282-3.

29. Neder JA, Arbex FF, Alencar MC, et al. Exercise ventilatory inefficiency in mild to end-stage COPD. Eur Respir J. 2015;45:377-87.

30. Turner DL. Cardiovascular and respiratory control mechanisms during exercise: an integrated view. J Exp Biol. 1991;160:309-40.

31. Gandevia SC. The perception of motor commands or effort during muscular paralysis. Brain. 1982;105:151-9.

32. Gandevia SC, Killian KJ, Campbell EJ. The effect of respiratory muscle fatigue on respiratory sensations. Clin Sci (Lond). 1981;60:463-6.

33. Caviedes IR, Delgado I, Soto R. Ventilatory inefficiency as a limiting factor for exercise in patients with COPD. Respir Care. 2012;57:583-9. 
34. Moreira MA, Medeiros GA, Boeno FP, Sanches PR, Silva Junior DP, Mueller AF. Oxygen desaturation during the six-minute walk test in COPD patients. J Bras Pneumol. 2014;40:222-8.

35. Andrianopoulos V, Franssen FM, Peeters JP, et al. Exercise-induced oxygen desaturation in COPD patients without resting hypoxemia. Respir Physiol Neurobiol. 2014;190:40-6.

36. Patessio A, Casaburi R, Carone M, Appendini L, Donner CF, Wasserman $\mathrm{K}$. Comparison of gas exchange, lactate, and lactic acidosis thresholds in patients with chronic obstructive pulmonary disease. Am Rev Respir Dis. 1993;148:622-6.

37. Pleguezuelos E, Esquinas C, Moreno E, et al. Muscular dysfunction in COPD: Systemic effect or deconditioning? Lung. 2016;194:249-57.

38. O'Donnell DE, D'Arsigny C, Fitzpatrick M, Webb KA. Exercise hypercapnia in advanced chronic obstructive pulmonary disease: the role of lung hyperinflation. Am J Respir Crit Care Med. 2002;166:663-8.

39. O'Donnell DE, Laveneziana P, Webb K, Neder JA. Chronic obstructive pulmonary disease: clinical integrative physiology. Clin Chest Med. 2014; 35:51-69.

40. Laveneziana P, Palange P, Ora J, Martolini D, O’Donnell DE. Bronchodilator effect on ventilatory, pulmonary gas exchange, and heart rate kinetics during high-intensity exercise in COPD. Eur J Appl Physiol. 2009;107:633-43.

41. Laveneziana P, Valli G, Onorati P, Paoletti P, Ferrazza AM, Palange P. Effect of heliox on heart rate kinetics and dynamic hyperinflation during high-intensity exercise in COPD. Eur J Appl Physiol. 2011;111:225-34.

42. Chiappa GR, Borghi-Silva A, Ferreira LF, et al. Kinetics of muscle deoxygenation are accelerated at the onset of heavy-intensity exercise in patients with COPD: relationship to central cardiovascular dynamics. J Appl Physiol (1985). 2008;104:1341-50.

43. Vasilopoulou MK, Vogiatzis I, Nasis I, et al. On- and off-exercise kinetics of cardiac output in response to cycling and walking in COPD patients with GOLD Stages I-IV. Respir Physiol Neurobiol. 2012;181:351-8.

44. Jolley CJ, Luo YM, Steier J, Rafferty GF, Polkey MI, Moxham J. Neural respiratory drive and breathlessness in COPD. Eur Respir J. 2015;45:355-64.

45. Guenette JA, Chin RC, Cory JM, Webb KA, O'Donnell DE. Inspiratory capacity during exercise: Measurement, analysis, and interpretation. Pulm Med. 2013;2013:956081.

46. Leblanc P, Summers E, Inman MD, Jones NL, Campbell EJ, Killian KJ. Inspiratory muscles during exercise: a problem of supply and demand. J Appl Physiol (1985). 1988;64:2482-9.

47. Laveneziana P, Webb KA, Wadell K, Neder JA, O'Donnell DE. Does expiratory muscle activity influence dynamic hyperinflation and exertional dyspnea in COPD? Respir Physiol Neurobiol. 2014;199:24-33.

48. Ciavaglia CE, Guenette JA, Langer D, Webb KA, Alberto NJ, O'Donnell DE. Differences in respiratory muscle activity during cycling and walking do not influence dyspnea perception in obese patients with COPD. J Appl Physiol (1985). 2014;117:1292-301.

49. Kyroussis D, Polkey MI, Hamnegard CH, Mills GH, Green M, Moxham J. Respiratory muscle activity in patients with COPD walking to exhaustion with and without pressure support. Eur Respir J. 2000;15:649-55.

50. Potter WA, Olafsson S, Hyatt RE. Ventilatory mechanics and expiratory flow limitation during exercise in patients with obstructive lung disease. J Clin Invest. 1971;50:910-9.

51. Mador MJ, Kufel TJ, Pineda LA, Sharma GK. Diaphragmatic fatigue and high-intensity exercise in patients with chronic obstructive pulmonary disease. Am J Respir Crit Care Med. 2000;161:118-23.

52. Gosselink R, Troosters T, Decramer M. Peripheral muscle weakness contributes to exercise limitation in COPD. Am J Respir Crit Care Med. 1996; 153:976-80

53. Charususin N, Gosselink R, McConnell A, et al. Inspiratory muscle training improves breathing pattern during exercise in COPD patients. Eur Respir J. 2016;47:1261-4.

54. Clanton TL, Levine S. Respiratory muscle fiber remodeling in chronic hyperinflation: dysfunction or adaptation? J Appl Physiol (1985). 2009;107: 324-35.
55. Maltais F, Decramer M, Casaburi R, et al. An official American Thoracic Society/European Respiratory Society statement: update on limb muscle dysfunction in chronic obstructive pulmonary disease. Am J Respir Crit Care Med. 2014;189:e15-62.

56. O'Donnell DE, Maltais F, Porszasz J, et al. The continuum of physiological impairment during treadmill walking in patients with mild-to-moderate COPD: patient characterization phase of a randomized clinical trial. PLoS One. 2014;9:e96574.

57. Woods PR, Olson TP, Frantz RP, Johnson BD. Causes of breathing inefficiency during exercise in heart failure. J Card Fail. 2010;16:835-42.

58. Sue DY. Excess ventilation during exercise and prognosis in chronic heart failure. Am J Respir Crit Care Med. 2011;183:1302-10.

59. Poon CS, Tin C, Song G. Submissive hypercapnia: Why COPD patients are more prone to $\mathrm{CO}_{2}$ retention than heart failure patients. Respir Physiol Neurobiol. 2015;216:86-93.

60. O'Donnell DE, Hamilton AL, Webb KA. Sensory-mechanical relationships during high-intensity, constant-work-rate exercise in COPD. J Appl Physiol (1985). 2006;101:1025-35.

61. O'Donnell DE, Voduc N, Fitzpatrick M, Webb KA. Effect of salmeterol on the ventilatory response to exercise in chronic obstructive pulmonary disease. Eur Respir J. 2004;24:86-94.

62. Porszasz J, Emtner M, Goto S, Somfay A, Whipp BJ, Casaburi R. Exercise training decreases ventilatory requirements and exercise-induced hyperinflation at submaximal intensities in patients with COPD. Chest. 2005;128:2025-34

63. Jensen D, Alsuhail A, Viola R, Dudgeon DJ, Webb KA, O'Donnell DE. Inhaled fentanyl citrate improves exercise endurance during high-intensity constant work rate cycle exercise in chronic obstructive pulmonary disease. J Pain Symptom Manage. 2012;43:706-19.

64. Parker CM, Fitzpatrick MF, O'Donnell DE. Physiology of Interstitial Lung Disease. In: Schwarz MI, King TE (eds). Interstitial Lung Disease. 5th Edition. Hamilton, ON: B.C. Decker; 2011. p. 61-79.

65. Widimsky J, Riedel M, Stanek V. Central haemodynamics during exercise in patients with restrictive pulmonary disease. Bull Eur Physiopathol Respir. 1977;13:369-79.

66. Cortes-Telles A, Forkert L, O'Donnell DE, Moran-Mendoza O. Idiopathic pulmonary fibrosis: new insights on functional characteristics at diagnosis. Can Respir J. 2014;21:e55-60.

67. Holland AE, Hill CJ, Conron M, Munro P, McDonald CF. Short term improvement in exercise capacity and symptoms following exercise training in interstitial lung disease. Thorax. 2008;63:549-54.

68. Egan JJ, Martinez FJ, Wells AU, Williams T. Lung function estimates in idiopathic pulmonary fibrosis: the potential for a simple classification. Thorax. 2005;60:270-3.

69. American Thoracic Society. Idiopathic pulmonary fibrosis: diagnosis and treatment. International consensus statement. American Thoracic Society (ATS), and the European Respiratory Society (ERS). Am J Respir Crit Care Med. 2000;161:646-64.

70. Nishimura Y, Hida W, Taguchi O, et al. Respiratory muscle strength and gas exchange in neuromuscular diseases: comparison with chronic pulmonary emphysema and idiopathic pulmonary fibrosis. Tohoku J Exp Med 1989;159:57-68.

71. O'Donnell DE, Ofir D, Laveneziana P. Patterns of cardiopulmonary response to exercise in lung disease. Eur Respir Monograph. 2007;159:57-68.

72. Agusti AG, Roca J, Gea J, Wagner PD, Xaubet A, Rodriguez-Roisin R. Mechanisms of gas-exchange impairment in idiopathic pulmonary fibrosis Am Rev Respir Dis. 1991;143:219-25.

73. Hughes JM, Lockwood DN, Jones HA, Clark RJ. DLCO/Q and diffusion limitation at rest and on exercise in patients with interstitial fibrosis. Respir Physiol. 1991;83:155-66.

74. Hamer J. Cause of low arterial oxygen saturation in pulmonary fibrosis. Thorax. 1964;19:507-14.

75. Weitzenblum E, Ehrhart M, Rasaholinjanahary J, Hirth C. Pulmonary hemodynamics in idiopathic pulmonary fibrosis and other interstitial pulmonary diseases. Respiration. 1983;44:118-27. 
76. Keogh BA, Lakatos E, Price D, Crystal RG. Importance of the lower respiratory tract in oxygen transfer. Exercise testing in patients with interstitial and destructive lung disease. Am Rev Respir Dis. 1984;129:S76-80.

77. Risk C, Epler GR, Gaensler EA. Exercise alveolar-arterial oxygen pressure difference in interstitial lung disease. Chest. 1984;85:69-74.

78. Johnson RL, Spicer WS, Bishop JM, Forster RE. Pulmonary capillary blood volume, flow and diffusing capacity during exercise. J Appl Physiol. 1960; 15:893-902.

79. Paintal AS. Mechanism of stimulation of type J pulmonary receptors. J Physiol. 1969;203:511-32.

80. Burdon JG, Killian KJ, Jones NL. Pattern of breathing during exercise in patients with interstitial lung disease. Thorax. 1983;38:778-84.

81. O'Donnell DE, Hong HH, Webb KA. Respiratory sensation during chest wall restriction and dead space loading in exercising men. J Appl Physiol (1985). 2000;88:1859-69.

82. Romer LM, Polkey MI. Exercise-induced respiratory muscle fatigue: implications for performance. J Appl Physiol (1985). 2008;104:879-88.

83. McConnell AK, Romer LM. Dyspnoea in health and obstructive pulmonary disease: the role of respiratory muscle function and training. Sports Med. 2004;34:117-32.

84. Leblanc P, Bowie DM, Summers E, Jones NL, Killian KJ. Breathlessness and exercise in patients with cardiorespiratory disease. Am Rev Respir Dis. 1986;133:21-5.

85. Leblanc P, Bowie DM, Summers E, Jones NL, Killian KJ. Clin Invest Med 1983;7(Suppl 2):80.

86. Edwards RH. Physiological analysis of skeletal muscle weakness and fatigue. Clin Sci Mol Med. 1978;54:463-70.

87. Durfee WK, Palmer KI. Estimation of force-activation, force-length, and force-velocity properties in isolated, electrically stimulated muscle. IEEE Trans Biomed Eng. 1994;41:205-16.

88. NHLBI Workshop. Respiratory muscle fatigue: report of the respiratory muscle fatigue workshop group. Am Rev Respir Dis. 1990;142:474-80.

89. Marciniuk DD, Sridhar G, Clemens RE, Zintel TA, Gallagher CG. Lung volumes and expiratory flow limitation during exercise in interstitial lung disease. J Appl Physiol (1985). 1994;77:963-73.

90. O'Donnell DE, Chau LK, Webb KA. Qualitative aspects of exertional dyspnea in patients with interstitial lung disease. J Appl Physiol (1985). 1998; 84:2000-9.

91. Jones NL, Rebuck AS. Tidal volume during exercise in patients with diffuse fibrosing alveolitis. Bull Eur Physiopathol Respir. 1979;15:321-8.

92. De TA, Yernault JC. Inspiratory muscle force in normal subjects and patients with interstitial lung disease. Thorax. 1980;35:92-100.

93. Baydur A, Alsalek M, Louie SG, Sharma OP. Respiratory muscle strength, lung function, and dyspnea in patients with sarcoidosis. Chest. 2001;120: $102-8$.
94. Bajwah S, Ross JR, Peacock JL, et al. Interventions to improve symptoms and quality of life of patients with fibrotic interstitial lung disease: a systematic review of the literature. Thorax. 2013;68:867-79.

95. Ferreira A, Garvey C, Connors GL, et al. Pulmonary rehabilitation in interstitial lung disease: benefits and predictors of response. Chest. 2009;135: 442-7.

96. Gandevia B, Hugh-Jones P. Terminology for measurements of ventilatory capacity; a report to the thoracic society. Thorax. 1957;12:290-3.

97. Killian KJ, Gandevia SC, Summers E, Campbell EJ. Effect of increased lung volume on perception of breathlessness, effort, and tension. J Appl Physio Respir Environ Exerc Physiol. 1984;57:686-91.

98. Chen Z, Eldridge FL, Wagner PG. Respiratory-associated thalamic activity is related to level of respiratory drive. Respir Physiol. 1992;90:99-113.

99. O'Donnell DE, Bertley JC, Chau LK, Webb KA. Qualitative aspects of exertional breathlessness in chronic airflow limitation: pathophysiologic mechanisms. Am J Respir Crit Care Med. 1997;155:109-15.

100. Laveneziana P, Webb KA, Ora J, Wadell K, O'Donnell DE. Evolution of dyspnea during exercise in chronic obstructive pulmonary disease: impact of critical volume constraints. Am J Respir Crit Care Med. 2011;184:1367-73.

101. Opie LH, Smith AC, Spalding JM. Conscious appreciation of the effects produced by independent changes of ventilation volume and of end-tidal pCO2 in paralysed patients. J Physiol. 1959;149:494-9.

102. Schwartzstein RM, Simon PM, Weiss JW, Fencl V, Weinberger SE. Breathlessness induced by dissociation between ventilation and chemical drive. Am Rev Respir Dis. 1989;139:1231-7.

103. Evans KC, Banzett RB, Adams L, McKay L, Frackowiak RS, Corfield DR. BOLD fMRI identifies limbic, paralimbic, and cerebellar activation during air hunger. J Neurophysiol. 2002;88:1500-11.

104. Banzett RB, Pedersen SH, Schwartzstein RM, Lansing RW. The affective dimension of laboratory dyspnea: air hunger is more unpleasant than work/ effort. Am J Respir Crit Care Med. 2008;177:1384-90.

105. von Leupoldt A, Sommer T, Kegat S, et al. Dyspnea and pain share emotion-related brain network. Neuroimage. 2009;48:200-6.

106. von Leupoldt A, Dahme B. Cortical substrates for the perception of dyspnea. Chest. 2005;128:345-54.

107. von Leupoldt A, Sommer T, Kegat S, et al. The unpleasantness of perceived dyspnea is processed in the anterior insula and amygdala. Am J Respir Crit Care Med. 2008;177:1026-32.

108. Davenport PW, Vovk A. Cortical and subcortical central neural pathways in respiratory sensations. Respir Physiol Neurobiol. 2009;167:72-86.

109. Pattinson K. Functional brain imaging in respiratory medicine. Thorax. 2015;70:598-600.

110. Wasserman K, Hansen JE, Sue DY (eds). Principles of exercise testing and interpretation: including pathophysiology and clinical applications. Lippincott Williams \& Wilkins. 2011. 